doi: 10.52370/TISC21263JO

\title{
THE ROLE OF EMPLOYER BRAND IN HOTEL COMPANIES DURING COVID-19 CRISIS
}

\author{
Jasmina Ognjanovićl ${ }^{\text {; Marijana Bugarčić }}{ }^{2}$
}

\begin{abstract}
Hospitality and tourism is one of economic braches which has been severely affected by the COVID-19 pandemic. Finding the ways and identifying the measures for recovering from the crisis which has been lasting for more than a year is the key task of hotel managers and leaders. The main objective of this paper is to examine the state of affairs in the hotel industry that has been devastated by COVID-19 and analyze the possible tools for human resource management in hotels, all with the aim of mitigating the consequences of the crisis. Inductive and deductive research methods were used for the needs of this analysis. One of the possible solutions for overcoming the crisis of human resource management is employer brand. Investing in employer brand may result in creating specific benefits for employees - functional, economic and psychological benefits. During the pandemic, the benefits for employees are expanded to job security, health protection and psychological recovery of employees.
\end{abstract}

Key Words: employer brand, hotel, COVID-19, human resource JEL classification: J24, J28, M54

\section{Introduction}

Over the past 12 months, COVID-19 pandemic has had a negative impact on the global economy and has caused greater uncertainty than any other crisis in the recent past (SARS 2003, financial crisis in 2008) (Kashyap \&

\footnotetext{
${ }^{1}$ Jasmina Ognjanović, PhD, Assistant Professor, University of Kragujevac, Faculty of Hotel Management and Tourism in Vrnjačka Banja, Vojvođanska 5A, 36210 Vrnjačka Banja, +38163608943, jasmina.lukic@kg.ac.rs

${ }^{2}$ Marijana Bugarčić, Research Assistant, University of Kragujevac, Faculty of Economics in Kragujevac, Liceja Kneževine Srbije 3, 34000 Kragujevac, +381621455993, msimic@kg.ac.rs
} 
Raghuvanshi, 2020). The pandemic has rapidly and harshly disrupted life and economies, and forced companies and governments to make hard decisions and choices in order to mitigate the risk in terms of population and economics health (Manuel \& Herron, 2020). Increased unemployment rate and reasons for encouraging people to stay at home resulted in significant drop of consumers' demand for numerous goods and services (Manuel \& Herron, 2020). Companies that operate in various industries "faced supply chain disruption, which reduced the quantity of output/production and increased the costs of production" (Manuel \& Herron, 2020, p. 236). The only industry that has been able to preserve its business operations during the pandemic is IT sector. It is foreseen that this sector will be affected during the later stages of the pandemic (Kashyap \& Raghuvanshi, 2020). Apart from the current COVID crisis, corporative leaders are facing other challenges, such as "climate change, income inequality, racial inequity, and healthcare cost and availability" (Yohn, 2020). In the stated circumstances, companies have two options: either to identify and respond to the above mentioned changes or to risk losing clients, suppliers and other stakeholders (Manuel \& Herron, 2020).

The COVID-19 pandemic has had a negative impact on a large number of industries throughout the world, especially in terms of labor-intensive economic activities which depend on high-level interaction between employees and buyers. Hospitality and tourism are based on human mobility and close interaction, and are thus the primary "recipients" of the pandemic consequences (Hao et al., 2020). Hospitality implies a set of activities where "people deal with people" (Barrows \& Bosselman, 1999), which makes human resource development crucial for hotel industry (Slavković \& Ognjanović, 2018). COVID-19 has disturbed the hotel industry and caused rapid reduction of industrial performance. Consequently, numerous employees lost their jobs and were made redundant (He et al., 2021). Therefore, it is of outmost importance to define the appropriate measures for mitigating the crisis and protecting the key hotel resource during the pandemic- employees. Hotels are addressing the challenge of designing the HRM system and process which would meet the market requirements and overcome pressure caused by the pandemic (Agarwal, 2021). The HRM practices can be of assistance in embracing social responsibility and showing empathy for the employees in the hospitality sector during the crisis (He et al., 2021). Adapting the HRM practices to the new circumstances of the crisis is crucial for the hospitality industry, as positive guest experience requires exceptional communication between employees and guests (Agarwal, 2021). 
The main objective of this paper is to analyze the state of affairs in the hospitality industry which has been affected by COVID-19, and examine the human resource management tools in hotels, all with the aim of mitigating the consequences of the crisis. The conclusions have been made by applying deductive and inductive research methods. This study is relevant because it analyzes the position of employees in hotels during the pandemic and proposes the possible tools for promoting their position. Therefore, the following research questions are to be answered:

1. Can human resources be crucial means for mitigating the effects of COVID-19 in the field of hospitality industry?

2. Can employer brand be considered as acceptable tool for human resource management in hospitality industry during the COVID-19 pandemic?

\section{Hotel industry during the COVID-19 pandemic}

The global outbreak of COVID-19 has had a negative impact on the entire tourism and hospitality industry (Guillet \& Chu, 2021; Awan et al., 2021). "Hundreds of thousands of employees in hotel and tourist facilities have faced serious threats to their health and job safety due to the uncertainty caused by COVID-19 pandemic" (He et al., 2021, p. 347). This crisis is different from previous crises which resulted in a significant drop in all types of demand worldwide (Guillet \& Chu, 2021). Even though clients in specific business activities expect digital solutions, the hospitality industry is one of the branches in which physical contact is essential for service provision (Awan et al., 2021). Lockdowns and social distancing have caused a rapid turnover drop in the field of hospitality and tourism, as the sector primarily relies on tourist mobility and personal services offered by employees (He et al., 2021).

According to the data presented by the World Tourism Organization (2021), in 2020, the tourism and hospitality industry recorded "the loss of 850 million to 1.1 billon international tourists; loss of US\$ 910 billion to US\$ 1.2 trillion in export revenues from tourism and put 100 to 120 million jobs at risk". Hotel company managers were under large pressure due to partial or complete closures, financial loss, fixed costs and uncertain shortterm and long-term demand for hotel occupancy (Jiang \& Wen, 2020; Guillet \& Chu, 2021). Hotels were forced to ask their employees to take unpaid leave, and postpone office and system maintenance (Lai \& Wong, 2020). Some estimates indicate (Yohn, 2020) that quarter of the total number of employees have been dismissed since the beginning of the 
pandemics. The COVID-19 outbreak has significantly reduced demand for hotel occupancy (Lai \& Wong, 2020), which resulted in the drop of key performance indicators in the hospitality industry (Awan et al., 2021; Guillet \& Chu, 2021). Hotel occupancy dropped in all countries by $50 \%$, and even more (Agarwal, 2021), while "average revenue-per-availableroom (RevPAR) dropped by $90 \%$ in the second quarter of 2020" (Le \& Phi, 2020, pp. 1-2). Moreover, the COVID-19 pandemic has had a negative impact on hotel industry performances in the Republic of Serbia. Figure 1 shows the net-occupancy rate per month in 2020. Based on the shown data, one can conclude that the net-occupancy rate started dropping rapidly in February 2020, reached its minimum in May (8.4\%), while the maximum rate was recorded in September (33.4\%).

Figure 1: Net-occupancy rate of bedrooms in hotels and similar accommodation in 2020 in Republic of Serbia- monthly data

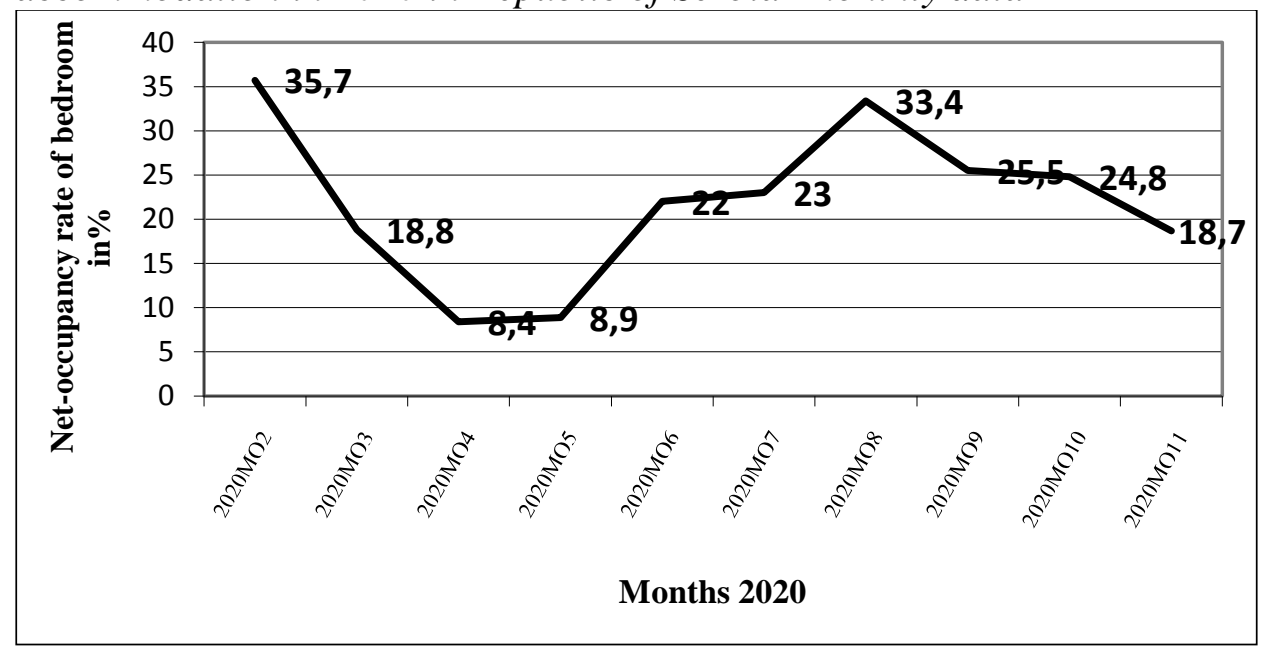

Source: Eurostat, 2021

The number of overnight stays in hotels in the Republic of Serbia has also decreased when compared to the same period last year (Figure 2). Information of the Statistical Office of the Republic of Serbia for October 2020 indicated that there were $49.3 \%$ less tourists if compared to the same period the previous year. The number of arrivals of foreign tourists compared to the previous October was reduced by $75 \%$, while the number of arrivals of domestic tourists was reduced by $20.7 \%$. Additionally, the total number of overnight stays of foreign and domestic tourists was decreased by $37.5 \%$, i.e. the number of overnight stays of foreign tourists decreased by $66.2 \%$, while the number of overnight stays of domestic 
tourists decreased by $14.9 \%$ (Statistical Office of the Republic of Serbia, 2020, p.58). Figure 2 indicates monthly data on percentage change in overnight stays in hotels and similar accommodation in Serbia in 2020 as compared to 2019. When compared to 2019, the largest deviation was recorded in April 2020 (-96.24\%).

Figure 2: Overnight stays in hotels and similar accommodation percentage change compared to same period previous year in the Republic of Serbia

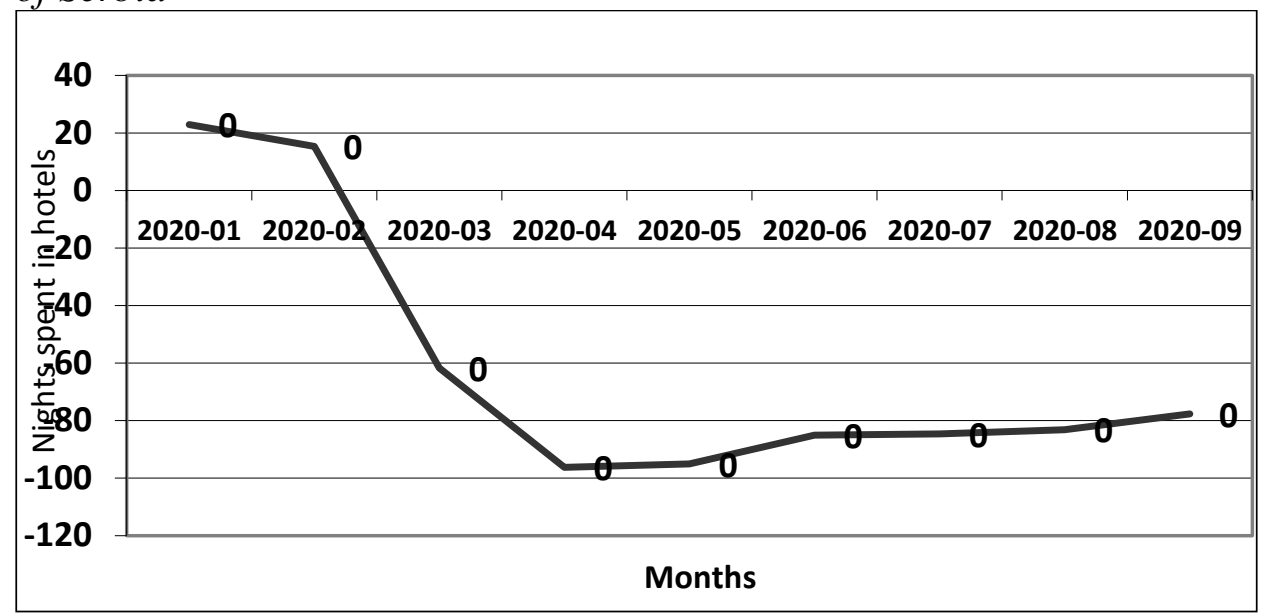

Source: Eurostat, 2021

COVID-19 still affects states worldwide and has serious and continuous impact on labor-intensive activities, such as tourism and hospitality (Knight et al., 2020). Current state of affairs in hospitality requires using new opportunities and developing innovative business models (Awan et al., 2021). This primarily refers to sharing human capital, developing new concept of service provision, as well as new ideas for promoting "staycation or holistay concept" (Awan et al., 2021) and safe behavior of employees, which have positive "impact on workplace safety, product service quality and corporate safety performance" (Zhang et al., 2020, p. 3366).

\section{Human resources in hospitality industry}

The hospitality industry is labor-intensive industry and its performance primarily depends on knowledge and skills of all employees (Ognjanović, 2017). Difference between a successful and unsuccessful company is in knowledge and skills (Dabić et al., 2021). Employees in hotels play a 
crucial role in creating top-quality services (Jung et al., 2021; Agarwal, 2021) and achieving superior performances (Simić et al., 2020). Therefore, a strategic approach to hospitality employee management, which will be based on developing specific benefits for employees, is essential. The HRM practices provide hotels with strategic advantage in all functional aspects, and consequently improve hotel business operations (Agarwal, 2021). Human resource management is decisive during the COVID-19 pandemic, as the primary objective of HRM practice is to support employees and prepare them for uncertain working environment (Agarwal, 2021).

Furthermore, employee-guest interaction is vital for creating the image of top-quality service (Kim et al., 2021). Positive guest experience depends on hotel employees' approach (Karatepe, 2013; Agarwal, 2021), i.e. "showing politeness, patience, and emotion, welcoming guests, and providing a serene atmosphere of comfort and relaxation" (Kim et al. 2021, p. 2). During COVID-19, guest experience can be improved by hotel employee safety behavior which would make guests feel safe and help them enjoy various hospitality-related activities (Zhang et al., 2020).

\section{Employment trend in hospitality industry during the COVID-19 crisis}

Before the outbreak of the pandemic, hotel industry recorded an economic growth which increased the need for employing talented and qualified personnel. Hotels in the EU member states and the Republic of Serbia documented a general trend of increasing employment until 2020. Thus, the demand for talented workforce became more and more extensive on the market. In terms of offer, the lack of talented individuals was the result of demographic transition, globalization and business liberalization. Disproportion between supply and demand for talented workforce often resulted in the "war for talents" among companies, which emphasized the need for developing the concept of employer brand. The aim of employer brand development is to enhance certain benefits for employees in order to attract and keep the talented personnel.

In terms of the observed 10-year period (210-2019), the EU countries recorded a continuous employment growth in the hospitality industry. The largest number of employees was employed in 2019 (more than 2.400.000). Additionally, the Republic of Serbia recorded significant employment growth until 2020. Employment fluctuations occurred between 2012 and 2107. In 2017, there were 20.700 employees in hospitality industry. 
Figure 3: Employed person in accommodation sector in European Unionquarterly data (data are given in thousands)

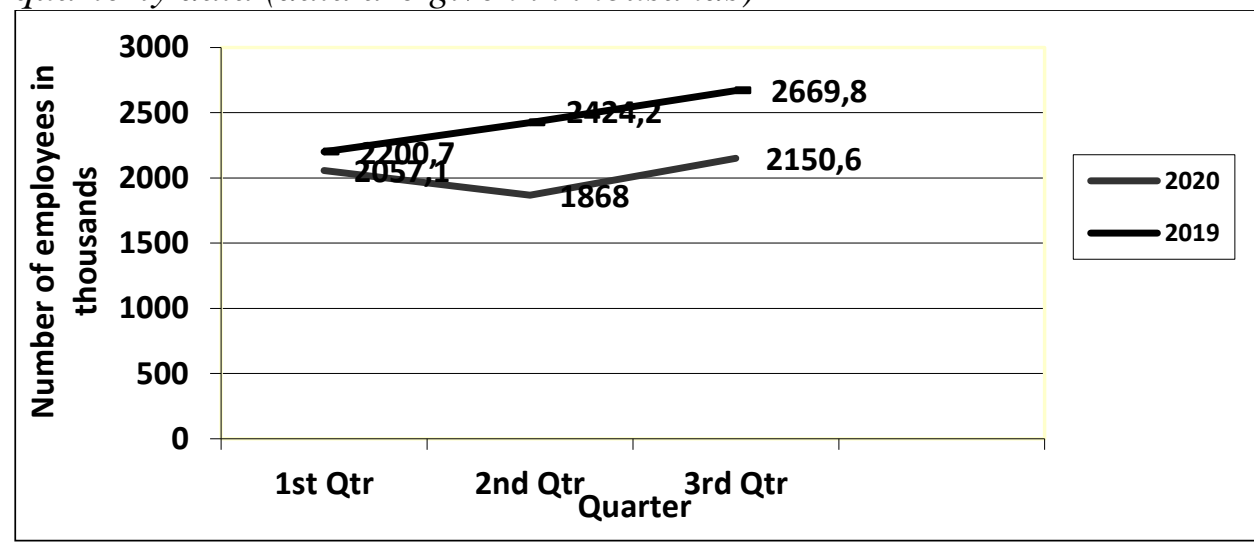

Source: Eurostat, 2021

Figure 4: Employed person in accommodation sector in the Republic of Serbia - quarterly data (data are given in thousands)

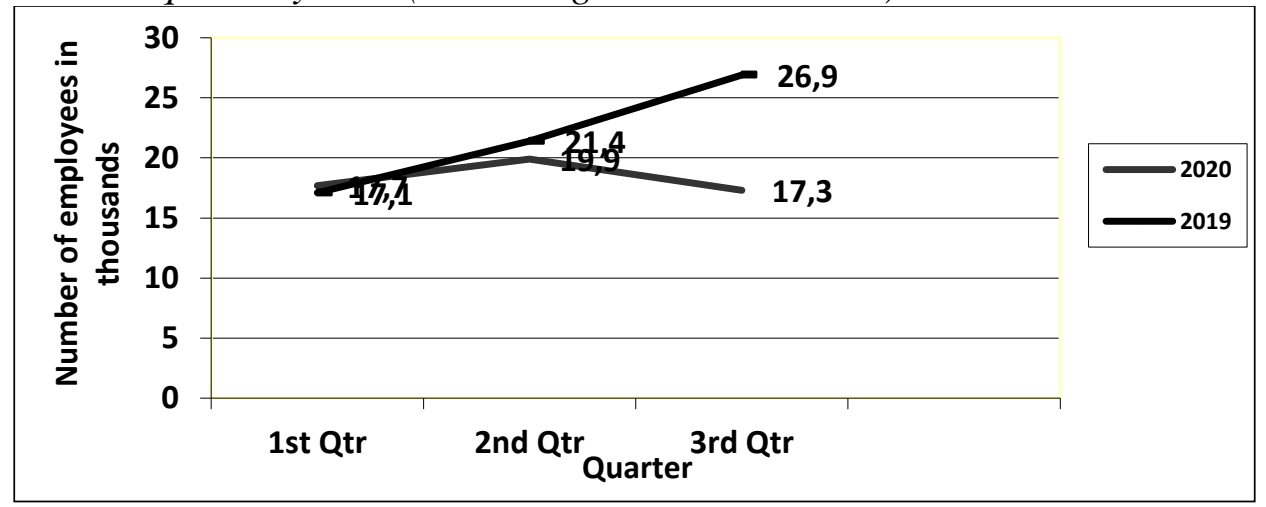

Source: Eurostat, 2021

During the COVID-19 pandemic, the hotel industry was the first industry which faced employment shock, rapid decrease "in the number of employees and increase in the number of employees on temporary leave" (Jung et al., 2021, p. 1). Figure 3 indicates the employment trend in the European Union in 2019 and 2020 by quarters. The number of employees in the third quarter of 2020 was decreased by $19.4 \%$ as compared to the same quarter 2019. Figure 4 shows the employment trend in the Republic of Serbia in 2019 and 2020 by quarters. In 2019, the hotel industry recorded employment growth by quarters. However, the employment rate decreased in the second quarter of 2020, and the same trend continued throughout the third quarter. 
The uncertainty of employment in the hotel industry caused by the pandemic is a threat to organizational performance and sustainability. Therefore, hoteliers should find appropriate solution in the field of human resource management (Jung et al., 2021). Job uncertainty triggers stress in employees and has a negative effect on their psychological state (Tian et al., 2014; Jung et al., 2021). Therefore, the promotion of employees' psychological recovery and overcoming fear due to the catastrophic consequences of COVID-19 are in the focus of interest of the scientists who analyze the state of affairs in the hospitality industry (He et al., 2021). Numerous studies have pointed out that human resource management has a direct impact on the psychological state of employees in the field of hospitality, as well as on their emotions, attitudes and behavior (Madera et al., 2017; He et al., 2021). Therefore, the employer brand should be developed further, as it represents a significant tool for providing employees with specific benefits.

\section{Employer brand in hospitality}

Employer branding philosophy aims at helping companies focus their activities on selling products/services to buyers, and putting emphasis on employees who take active part in the implementation of business objectives and delivery of products/services (Ognjanović, 2020). The employer brand concept is founded on the resource-based view (Kashyap \& Verma, 2018), which implies that the internal resources of a company are the ground for creating value and sustainable competitive advantage. Human resources are crucial for creating hotel's values (Slavković \& Ognjanović, 2018). Additionally, "the development of hotel industry is based on various types of knowledge, i.e. knowledge of consumers' needs, the ways of creating services and methods of their differentiation" (Ognjanović, 2017, p. 128). Consequently, the development of employer brand shall provide specific benefits for employees and improve their knowledge, skills, experience and efficiency of their actions. "Employer brand represents an intangible asset which is the result of the successful implementation of employer branding strategy that promotes the company as exceptional employer, provides the candidates with realistic expectations and fulfills the promises made to all employees" (Ognjanović, 2020 , p. 65). The following studies point out the relevance of employer brand and support its importance for: employee satisfaction (Ognjanović \& Slavković, 2019; Tanwar \& Prasad, 2016), employee loyalty (BenraissNoailles \& Viot, 2020) and workforce performance (Ognjanović, 2020). 
The employer brand is focused on providing appropriate dimensions (benefits) for employees and potential employees. The benefits of employer brand imply all "functional, psychological and economic benefits" (Ambler $\&$ Barrow, 1996, p. 187). Functional benefits refer to the specificities of the workplace, content of business tasks and perspective of professional career development. Psychological benefits imply the feeling of belonging to the company and active involvement of each employee in the activities of the company which has engaged her/him. Economic benefits include the amount of financial and non-financial compensations that employees receive based on their effort and work. Other employer brand dimensions have derived from the above stated primary classification, all based on the needs of the company, employees' requirements and events on the labor market (Tanwar \& Prasad, 2016; Deepa \& Baral, 2019; Kashive et al., 2020). The expansion of the above stated dimensions implies developing knowledge, abilities and experience of employees, as well as their desire and motivation to do their best, be creative and achieve maximum productivity, all of which have a positive effect on guest satisfaction (Yohn, 2020). The development of employer brand is especially important during the COVID-19 pandemic, as it focuses on the improvement of three new dimensions: job security, health protection and psychological recovery of employees. Job security implies providing minimum risk of losing a job during the pandemic. Health protection includes securing free health service for all employees and providing compensation in the case of sick leave. The psychological recovery of employees is significant both during regular business operations and during the pandemic. Being a laborintensive activity, hoteliers' job requires sacrificing, working long hours, as well as finding enough time to rest.

The essence of employer brand development is to attract and keep talented individuals in a hotel. This can be achieved by improving employer brand dimensions. Investing in such assets implies significant financial assets, all with the aim of achieving long-term effects. Therefore, it is of crucial importance to analyze the state of affairs at the hotel industry labor market and to assess supply-demand ratio in order to make an adequate evaluation of cost-effectiveness of employer brand development.

\section{Proposing measures for overcoming COVID-19 crisis in hospitality industry}

The COVID-19 crisis has forced hotels to adjust their business operations to the new circumstances. Hotels should focus their services on a group of 
guests who are frightened and under a serious financial burden (Awan et al., 2021). Employees must also pay attention to the changes in guest behavior (Jiang \& Wen, 2020; Guillet \& Chu, 2021). Therefore, the major challenge is to differentiate, innovate and transform guest experience (Awan et al., 2021). Having in mind that the pandemic has affected hotels all over the world, authors Jiang \& Wen (2020) indicate that researchers should work on enhancing theoretical and practical knowledge in key hospitality sectors in order to help hotels recover efficiently from the disaster. Due to the crisis, hoteliers have to introduce and maintain safety strategies and safety operational standards at a very high level (Zhang et al., 2020). Guests have to believe that a hotel has implemented all the necessary measures to protect the health of the clients (Guillet \& Chu, 2021). Hotel safety leadership and employee safety behavior are of crucial importance for all hotels, as they ensure safe and satisfactory service quality, guest and employees' health, and make significant contribution to achieving satisfactory hotel performances (Zhang et al., 2020).

The crisis made employees master new techniques for hosting guests. Poor service during the COVID-19 pandemic would probably result in extremely negative reactions of guests, which may be devastating for a hotel's reputation (Agarwal, 2021). This leads to the conclusion that employees' experience is one of the crucial strategic priorities in hotel management during COVID-19 (Yohn, 2020). Experience that a company offers its employees should be planned very carefully, i.e. in the same way the customer approach is planned (Yohn, 2020). Aside from human resource management, Guillet \& Chu (2021) conclude that revenue management is still the key issue, especially during the crisis that hotel companies are facing.

Economic loss in hospitality sector is more than obvious. A possible solution to this problem is focusing on the internal control of costs and state subsidies, followed by tailoring the hotel services, transforming business structures and requiring help from the Government institutions (Knight et al., 2020). Guillet \& Chu (2021) point out that hotels may implement the following measures in order to reduce loss: furloughing staff, reducing costs and pivoting online. Aguinis et al. (2020) emphasize the importance of CSR practice that the employees should implement during the pandemic. Awan et al. (2021) conclude that the crisis caused by COVID-19 requires remodeling of the hotel service design, especially in terms of sanitary and disinfection activities, as well as redesigning the entire infrastructure and introducing new types of offers. As the customers are much more 
concerned about their health, hotel hygiene should be on top of the list for creating new business model (Guillet \& Chu, 2021). Yu et al. (2021) point out the significance of hygiene, as one of the possible models that institutions propose for fighting against COVID-19. Aside from precaution, as key measure, the authors state that hygiene and cleanness are crucial for successful business operations, as they were insisted upon after the major health crisis SARS in 2003 (Jiang \& Wen, 2020). Even during the crisis which occurred before SARS, hygiene and cleanness had been the topics of numerous discussions which aimed at recovering hospitality industry (Chien \& Law, 2003; Jiang \& Wen, 2020).

Spreading of the pandemic made the hotel industry recovery even harder and longer, and thus crisis management strategies should be adjusted to the new circumstances (Lai \& Wong, 2020). Kashyap \& Raghuvanshi (2020) identified 6 key factors of company success during the pandemic: "effective communication, social distancing, adopting new technology, modifying the rules and regulation at workplace, sealing the borders of the territory and strong leadership and government control" (p. 358). Some authors (Hao et al., 2020; Kashyap \& Raghuvanshi, 2020; Le \& Phi, 2020) have proposed appropriate management framework for managing hotels during the crisis. Hao et al. (2020) suggest taking the following steps in the field of management:

1. The first step implies thorough analysis of the entire disaster management process, after which the focus should be put on hotel property and analysis of the factors which have affected or may affect the hotel industry;

2. The second step refers to the principles which may help companies focus and redirect their actions during the various phases of the crisis;

3. The third step implies defining strategies which may be applied for mitigating the effects that the pandemic has had on the hospitality industry: leadership and communication strategies; human resource strategies, service provision strategies; CSR strategies; finance strategies; disaster management standard operating procedure.

\section{Employer brand as human resource management tool used for overcoming hotel company crisis}

COVID-19 has affected tourism and hospitality so severely that some estimates indicate that the industry would need years to recover and establish the normal work regime (Lai \& Wong, 2020). This situation requires changing the hotel management approach and shifting focus from 
the reactive to proactive one, in terms of epidemic prevention, human resource, maintenance and marketing practices (Lai \& Wong, 2020). The implementation of the measures taken during the COVID-19 crisis requires engaging human resources. Additionally, the impression that hotel organization will make on guests during the pandemic depends exclusively on the knowledge and skills of human resources.

The primary objective of employer brand is to provide appropriate benefits to employees and potential employees. During the COVID-19 crisis, hotels have faced challenges, such as how to avoid dismissing employees and look after their personnel. Investing in employer brand requires large financial assets which, in terms of the pandemic and limited business operations, represent a substantial expense for hotels. Numerous hotels which have recorded a very low net-occupation rate find it very hard to invest in employer brand. However, hotels must invest in order to revive their business operations after the pandemic. All proposed measures (client behavior monitoring, hygiene, revenue analysis) are to be implemented by engaging employees. It is evident that hotel recovery process should start from its employees. The best way to motivate employees to give their maximum and help hotels overcome crisis is to provide employees with appropriate benefits. Employer brand has proved to be one of the most effective practical tools. Before the crisis, employer brand was used for providing benefits in terms of employee training and development, providing compensations and benefits, and securing psychological benefits. It seems that employer brand plays an even more significant role during the crisis in terms of providing working conditions which secure health protection, job security and psychological recovery of employees during the pandemic. Hotel management must focus on creating safe health and hygiene conditions for all employees. Employee satisfaction will definitely result in guest satisfaction.

\section{Conclusion}

The cumulative costs of the pandemic are not known, but the study conducted by Jordão et al. (2020) revealed that previous pandemics with a high mortality rate resulted in an extended period of recovery and shift in returns between labor and capital (Manuel \& Herron, 2020). Changes were caused by increased savings, decrease in workforce offer, long period of low real interest rates and a decade of slower growth (Manuel \& Herron, 2020). The COVID-19 pandemic is not over yet, and thus it is assumed that 
hospitality and tourism will need time and additional investments in order to overcome the crisis.

A detailed overview of literature offers answers to many research questions. Having in mind the impact that hospitality industry has on the national economy, the recovery of this industry should start from the customer in terms of monitoring the changes in customer behavior and demands (Awan et al., 2021). Therefore, researchers should find a way to use data on customer behavior which is based on the history of their consumption before and after the pandemic (Jiang \& Wen, 2020). It is essential to orientate on the concept of "new normal" for the customers and "re-designing" the service provisions for the hotel industry (Awan et al., 2021). Monitoring the changes in guest behavior, identifying and implementing new requests are to be carried out by employees in hospitality industry. All of the above is the answer to the first research question, bearing in mind that human resources are crucial for the initiation of the process of hotel recovery from the consequences of the pandemic.

Employee satisfaction and safety should be dealt with, even during the pandemic. Therefore, employer brand is an important tool for providing specific benefits for all employees. During the pandemic, benefits are expanded to job security, health protection and psychological recovery of employees. Employees who feel safe and protected, and who are aware that their company looks after them can establish exceptional communication with guests and contribute to hotel guests' satisfaction and safety. This is the answer to the second research question, as employer brand development emphasizes that hotels look after their employees even in the time of crisis, which is the key factor for employee motivation and satisfaction growth.

Future research could be based on analyzing the impact of employer brand on employees' satisfaction and engagement during the pandemic. Additionally, it would be useful to analyze demands/benefits of the employees during the pandemic crisis. Moreover, future research could focus on the analysis of financial results achieved by hotel companies in 2020 , i.e. the year of the outburst of the COVID-19 pandemic.

\section{References}

1. Agarwal, P. (2021). Shattered but smiling: Human resource management and the wellbeing of hotel employees during COVID-19. International 
Journal of Hospitality Management, Vol. 93 (2021). Available online 19 November 2020, Doi: 10.1016/j.ijhm.2020.102765

2. Aguinis, H., Villamor, I., Gabriel, K. (2020). Understanding employee responses to COVID-19: a behavioral corporate social responsibility perspective. Management Research: Journal of the Iberoamerican Academy of Management, Vol. 18, No. 4, 421-438.

3. Ambler, T., Barrow S. (1996). The employer brand. The Journal of Brand Management, Vol. 4, No. 3, 185-206.

4. Awan, M.I., Shamim, A., Ahn, J. (2021). Implementing 'cleanliness is half of faith' in re-designing tourists, experiences and salvaging the hotel industry in Malaysia during COVID-19 pandemic. Journal of Islamic Marketing, Article in press.

5. Barrow, C., Bosselman, R. (1999). Hospitality Management Education, Haworth Hospitality Press, New York.

6. Benraiss-Noailles, L., Viot, C. (2020). Employer brand equity effects on employees well-being and loyalty. Journal of Business Research, Article in press.

7. Chien, G.C., Law, R. (2003). The impact of the severe acute respiratory syndrome on hotels: a case study of Hong Kong. International Journal of Hospitality Management, Vol. 22, No. 3, 327-332.

8. Dabić, M., Stojčić, N., Simić, M., Potocan, V., Slavković, M., Nedelko, Z. (2021). Intellectual agility and innovation in micro and small businesses: The mediating role of entrepreneurial leadership. Journal of Business Research, Vol. 123, 683-695.

9. Deepa, R., Baral, R. (2019). Importance-performance analysis as a tool to guide employer branding strategies in the IT-BPM industry. Journal of Organizational Effectiveness: People and Performance, Vol. 6, No. 1, 7795.

10. Eurostat (2021). European Statistical, European Commission. Available at: https://appsso.eurostat.ec.europa.eu/nui/submitViewTable Action.do, (2 February 2021). 
11. Guillet, B.D., Chu, A.M.C. (2021). Managing hotel revenue amid the COVID-19 crisis. International Journal of Contemporary Hospitality Management, Article in press.

12. Hao, F., Xiao, Q., Chon, K. (2020). COVID-19 and China's Hotel Industry: Impacts, a Disaster Management Framework, and Post-Pandemic Agenda. International Journal of Hospitality Management, Vol. 90 (2020), (05 August 2020).

13. He, J., Mao, Y., Morrison, A.M., Coca-Stefaniak, A. (2021).On being warm and friendly: the effect of socially responsible human resource management on employee fears of the threats of COVID-19. International Journal of Contemporary Hospitality Management, Vol. 33, No. 1, 346366.

14. Jiang, Y., Wen, J. (2020). Effects of COVID-19 on hotel marketing and management: a perspective article. International Journal of Contemporary Hospitality Management, Vol. 32, No. 8, 2563-2573.

15. Jung, H.S., Jung, Y.S., Yoon, H.H. (2021). COVID-19: The effects of job insecurity on the job engagement and turnover intent of deluxe hotel employees and the moderating role of generational characteristics. International Journal of Hospitality Management, Vol. 92 (2021). Available online 7 October 2020.

16. Karatepe, O.M. (2013). High-performance work practices, work social support and their effects on job embeddedness and turnover intentions. International Journal of Contemporary Hospitality Management, Vol. 25, No. 6, 903-921.

17. Kashive, N., Khanna, V.T., Bharthi, M.N. (2020). Employer branding through crowdsourcing: understanding the sentiments of employees. Journal of Indian Business Research, Article in press.

18. Kashyap, A., Raghuvanshi, J. (2020). A preliminary study on exploring the critical success factors for developing COVID-19 preventive strategy with an economy centric approach. Management Research: Journal of the Iberoamerican Academy of Management, Vol. 18, No. 4, 357-377. 
19. Kashyap, V., Verma, N. (2018). Linking dimensions of employer branding and turnover intentions. International Journal of Organizational Analysis, Vol. 26, No. 2, 282-295.

20. Kim, S., Kim, J., Badu-Baiden, F., Giroux, M., Choi, Y. (2021). Preference for robot service or human service in hotels? Impacts of the COVID-19 pandemic. International Journal of Hospitality Management, Vol. 93 (2021), (4 December 2020).

21. Knight, D., Xiong, L., Lan, W., Gong, J. (2020). Impact of COVID-19: research note on tourism and hospitality sectors in the epicenter of Wuhan and Hubei Province, China. International Journal of Contemporary Hospitality Management, Vol. 32, No. 12, 3705-3719.

22. Lai, I.K.W., Wong, J.W.C. (2020).Comparing crisis management practices in the hotel industry between initial and pandemic stages of COVID-19. International Journal of Contemporary Hospitality Management, Vol. 32, No. 10, 3135-3156.

23. Le, D., Phi, G. (2020). Strategic responses of the hotel sector to COVID-19: Toward a refined pandemic crisis management framework. International Journal of Hospitality Management, Article in press.

24. Madera, J.M., Dawson, M., Guchait, P., Belarmino, A.M. (2017). Strategic human resources management research in hospitality and tourism. International Journal of Contemporary Hospitality Management, Vol. 29, No. 1, 48-67.

25. Manuel, T., Herron, T. (2020). An ethical perspective of business CSR and the COVID-19 pandemic. Society and Business Review, Vol. 15, No. 3, 235-253.

26. Ognjanović (2020). Employer brand and workforce performance in hotel companies. Hotel and Tourism Management, Vol. 8, No. 2, 65-78.

27. Ognjanović, J., Slavković, S. (2019). Impact of employer brand on employees statisfaction in Serbian hotel enterprises, in: D. Cvijanović et al. (Eds.), Tourism in Function of Development of the Republic of Serbia Tourism as a Generator of Employment, Faculty of Hotel Management and Tourism in Vrnjačka Banja University of Kragujevac, Vrnjačka Banja, pp. 254-271. 
28. Ognjanović, J. (2017). Relations of Intellectual Capital Components in Hotel Companies. Industrija, Vol. 45, No. 2, 181-196.

29. Jordão, R.V.D., Novas, J., Gupta, V. (2020). The role of knowledgebased networks in the intellectual capital and organizational performance of small and medium-sized enterprises. Kybernetes, Vol. 49, No. 1, 116140.

30. Simić, M., Slavković, M., Aleksić, V. S. (2020). Human Capital and SME Performance: Mediating Effect of Entrepreneurial Leadership. Management: Journal of Sustainable Business and Management Solutions in Emerging Economies, Vol. 25, No. 3, 23-33.

31. Slavković, M., Ognjanović, J. (2018). Impact of Human Capital on Business Performance of Hotel Entreprises in Serbia. TEME, Vol. XLII, No. 4, 1339-1355.

32. Statistical Office of the Republic of Serbia (2020). Monthly statistical bulletin 10/2020 Available at: https://www.stat.gov.rs/en-us/publikacije/ publication/? $\mathrm{p}=12816$

33. Tanwar, K., Prasad, A. (2016). The effect of employer brand dimensions on job satisfaction: gender as a moderator. Management Decision, Vol. 54, No. 4, $854-886$.

34. Tian, Q., Zhang, L., Zou, W. (2014). Job insecurity and counterproductive behavior of casino dealers: the mediating role of affective commitment and moderating role of supervisor support. International Journal of Hospitality Management, Vol. 40, 29-36.

35. World Tourism Organization (UNWTO). The first global dashboard for tourism insights. Available at: https://www.unwto.org/unwto-tourismdashboard, (28 January 2021).

36. Yohn, D.L. (2020). Brand authenticity, employee experience and corporate citizenship priorities in the COVID-19 era and beyond. Strategy \& Leadership, Vol. 48, No. 5, 33-39.

37. Yu, J., Seo, J., Hyun, S.S. (2021). Perceived hygiene attributes in the hotel industry: customer retention amid the COVID-19 crisis. International Journal of Hospitality Management, Vol. 93 (2021), (29 November 2020). 
38. Zhang, J., Xie, C., Wang, J., Morrison, A., Coca-Stefaniak, A. (2020). Responding to a major global crisis: the effects of hotel safety leadership on employee safety behavior during COVID-19. International Journal of Contemporary Hospitality Management, Vol. 32, No. 11, 3365-3389. 